\title{
Constraint on the geochemical stage causing tetrad effect in kimuraite: Comparative studies on kimuraite and its related rocks, from REE pattern and Nd isotope ratio
}

\author{
TASuKu AKagi, ${ }^{1}$ Shun'ICHI NAKai, ${ }^{2}$ Hiroshi Shimizu ${ }^{3}$ and AKImasa Masuda ${ }^{4}$
}

${ }^{1}$ Faculty of Agriculture, Tokyo University of Agriculture and Technology, Saiwai-cho, Fuchu, Tokyo 183, Japan

${ }^{2}$ Laboratory for Earthquake Chemistry, Faculty of Science, University of Tokyo, Hongo, Bunkyo-ku, Tokyo 113, Japan

${ }^{3}$ Department of Earth Sciences, Faculty of Science, Kumamoto University, Kurokami, Kumamoto 860, Japan

${ }^{4}$ Department of Chemistry, University of Electro-communications, Chofu, Tokyo 182, Japan

(Received February 24, 1995; Accepted January 11, 1996)

Our careful analysis (Akagi et al., 1993) disclosed a W type tetrad effect in kimuraite, an REE carbonate mineral. To put constraint on the genetic stage responsible for the appearance of the effect, rare earth element (REE) abundances were compared between kimuraite and its paragenetic mineral (lanthanite) and between kimuraite and its host rock. The Nd isotopic compositions of kimuraite and the host rock were also compared.

Neodymium isotopic analyses conclude that the REE in kimuraite has a different source to its host rock. The similar magnitude of the tetrad effect among the paragenetic minerals of kimuraite rules out the process of mineralization as the stage responsible for the tetrad effect. It is inferred that kimuraite and lanthanite formed in situ from aqueous solutions enriched in REE which had infiltered the fissures of the host rock. This solution is considered to be responsible primarily for the tetrad effect of kimuraite.

\section{INTRODUCTION}

Kimuraite $\left[\mathrm{CaY}_{2}\left(\mathrm{CO}_{3}\right)_{4} \cdot 6 \mathrm{H}_{2} \mathrm{O}\right]$ is an REE carbonate mineral found recently at Higashi Matsuura-gun, Saga Prefecture, Japan. The mineral was described and its chemical formula determined by Nagashima et al. (1986). Kimuraite occurs as a fissure-filling mineral in alkali basalt along with genetically related minerals of lokkaite $\left[\mathrm{CaY}_{4}\left(\mathrm{CO}_{3}\right)_{7} \cdot 9 \mathrm{H}_{2} \mathrm{O}\right]$ and lanthanite $\left[(\mathrm{Nd}, \mathrm{La})_{2}\left(\mathrm{CO}_{3}\right)_{3} \cdot 8 \mathrm{H}_{2} \mathrm{O}\right]$. The operation of a tetrad effect was discovered in this mineral by our careful analysis (Akagi et al., 1993). Unlike the chondrite normalized REE patterns of most rock samples, the pattern of kimuraite is not a smooth one (Fig. 1). Instead, one can see a series of four curves, each curve consisting of four contiguous elements [La-(Ce)-Pr-Nd; (Pm)-Sm-Eu-Gd; Gd-Tb-Dy-Ho; and Er-Tm-Yb-Lu].

The tetrad effect results from partitioning, producing a wave-like pattern in the diagram of $\log K$ (partition coefficient) vs. REE atomic number (Peppard et al., 1969; Kagi et al., 1993) or in the chondrite-normalized REE pattern (Masuda and Ikeuchi, 1979; Masuda et al., 1987; Masuda and Akagi, 1989; Liu et al., 1993). Four contiguous elements, La-Ce-Pr-Nd, Pm-Sm-Eu-Gd, Gd-TbDy-Ho and Er-Tm-Yb-Lu, form each of the waves. Physical chemists have attributed the tetrad effect to the repulsion energy of $4 \mathrm{f}$ orbital electrons, and both the refined spin-pairing energy theory (Jørgensen, 1979) and its improved theory (Kawabe, 1992) succeeded in endorsing such features of the effect. It is true that full credit has not been made on the tetrad effect in natural samples (McLennan, 1994), leaving us to consider 


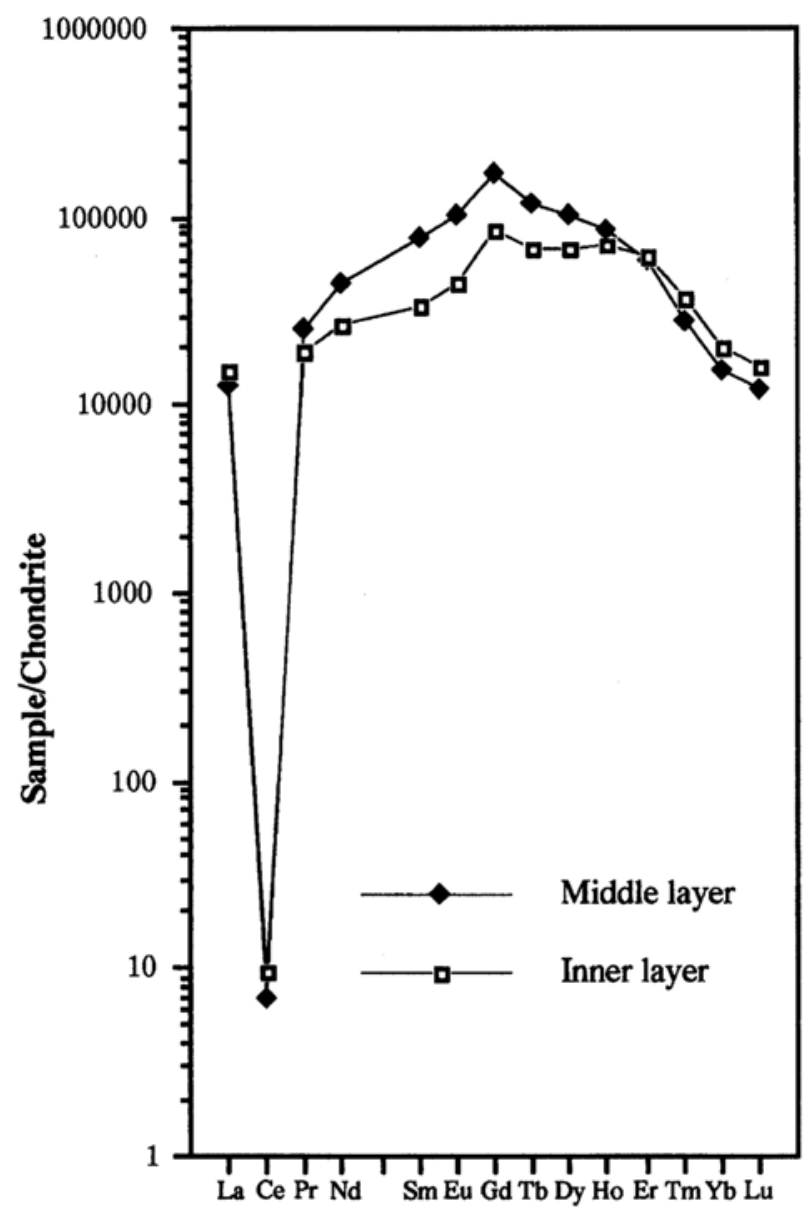

Fig. 1. REE patterns of kimuraites, cited from Akagi et al. (1993). The samples are kimuraites (middle and inner layers). Normalizing values are from Masuda et al. (1973) and Masuda (1975).

that the reason for the disapproval of the effect lies in lack of a straightforward method to prove the effect directly. There is always uncertainty in defining the two responsible coexisting phases in the complexity of nature. If we take the most geochemical benefit from the tetrad effect, however, the conditions necessary to activate the tetrad effect have to be investigated.

According to Masuda et al. (1987), the tetrad effect is classified into two conjugate types; the W type has concave-upward waves; the M type convex-upward waves. Seawaters and groundwaters were shown to have the W type tetrad effect and some rocks to have the $M$ type tetrad effect. These two types reflect the mutually opposing distribution characteristics of the tetrad effect. From the theoretical discussion based on electron repulsion and "electron donating" (or expanding) effect, it is considered that the distribution ratio of an organic phase to an aqueous phase shows the M-type tetrad effect. Analogously or rather empirically one can present the general rule that the distribution ratio of a solid phase to an aqueous phase shows the M-type tetrad effect.

Kimuraite shows a W-type tetrad effect. It is important to know when and how the tetrad effect was in operation during the formation history of kimuraite. We have investigated the genesis of kimuraite, mainly the relationship between kimuraite and its host rock, by geochemical means, 
in the hope that such studies will disclose the geochemical conditions needed to induce the tetrad effect in question.

\section{EXPERIMENTS}

\section{Samples}

A basalt containing kimuraite and lanthanite in fissures was sampled at Higashi Matsuura-gun, Saga Prefecture. A photograph of the kimuraitebearing basalt used in the present study is shown in Fig. 2. This kimuraite specimen is identical to that investigated in our earlier study. The specimen has a spherical habit with a radius of about 12 $\mathrm{mm}$ (Fig. 2), and a triple-layered structure with a clear boundary between the layers. The crystals of the middle and inner layers are kimuraites, and are opaque and transparent with pink color, respectively. Kimuraite (middle layer) is covered by a thin shell of lanthanite (the outer layer). Each mineral was separated by hand-picking and identified using X-ray diffraction. Another basalt (basalt-B) was sampled from the same body of the

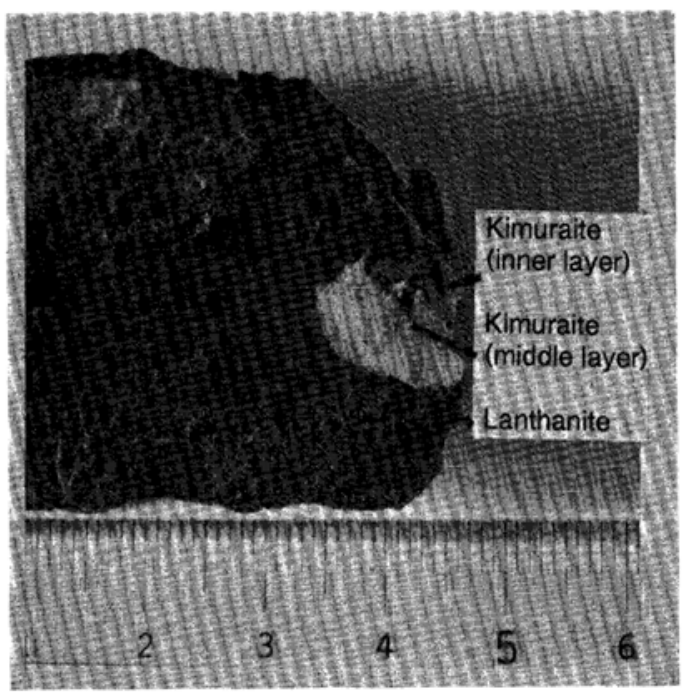

Fig. 2. Photograph of basalt with fracture-filling kimuraite. Although not readily apparent from the photograph, the kimuraite (middle layer) is coated with a thin layer of lanthanite. One small division equals one $\mathrm{mm}$. host rock of kimuraite, but showed no distinct fissures. This was analysed as a reference composition of the host rock (basalt-A) of kimuraite.

\section{Analytical procedures}

The REE carbonate minerals were dissolved in $\mathrm{HCl}$. Basalt samples were digested with $\mathrm{HF}$, $\mathrm{HClO}_{4}$, and $\mathrm{HCl}$. REE were separated from major elements by cation exchange column packed with AG 50W-X8 resin using $\mathrm{HCl}$ eluent. For isotopic studies, Nd was further separated from other REE on another cation exchange column using $\alpha$-HIBA (hydroxy-iso-butyric acid) eluent. REE abundances in all of the samples were determined by isotopic dilution with a JEOL JMS-05RB mass spectrometer. The precision of REE determination was better than $1 \%(1 \sigma)$. The concentrations of $\mathrm{Ce}$ in kimuraites and lanthanite were extremely low compared with those of the neighboring elements, and the separation of Ce was carried out using $\alpha$ HIBA to suppress the interference by isobaric species, but the precision of the abundance measurement was as poor as $10 \%$, probably owing to the imperfect resolution from the mass peaks of neighboring ${ }^{139} \mathrm{La}$ and ${ }^{141} \mathrm{Pr}$.

A leaching experiment was done on basalt-A. The powdered sample was leached in $0.5 \mathrm{~N} \mathrm{HCl}$ with ultrasonic agitation for $20 \mathrm{~min}$ at a room temperature. The leached basalt was digested as described above and the REE abundances were measured by isotope dilution. The procedure for REE separation was the same as that used for other samples.

The REE concentrations of kimuraite were measured also with an inductively coupled plasma source-mass spectrometer (ICP-MS), VG Plasma Quad. We prepared a special standard whose REE composition matches that of kimuraite and were able to achieve fairly precise measurements with the ICP-MS. The precision and accuracy of the analytical results for kimuraite were discussed in detail in our earlier paper (Akagi et al., 1993).

A VG 354 mass spectrometer was used for the neodymium isotopic ratio measurement. Measured isotope ratios were normalized to ${ }^{146} \mathrm{Nd} /{ }^{144} \mathrm{Nd}=$ 0.7219 . The typical rate of precision $(2 \sigma)$ of ${ }^{143} \mathrm{Nd} /$ 
${ }^{144} \mathrm{Nd}$ was 0.000005 , which corresponds to 0.1 in $\varepsilon_{\mathrm{Nd}}$ value.

\section{RESULTS}

REE patterns of kimuraite, lanthanite and basalts

The REE abundances of kimuraite (inner and middle layers of the specimen shown in Fig. 2), lanthanite (outer layer) and basalts are summarized in Table 1. The data on the abundances of the two kimuraite samples were taken from our previous paper (Akagi et al., 1993). The coupling with isotope dilution and ICP-MS offers accurate and precise analyses as discussed previously (Akagi et al., 1993); our results are shown in chondrite normalized REE patterns (Fig. 1). The two kimuraites have almost duplicate patterns with a maximum at $\mathrm{Gd}$, and a link of four contiguous elements [La-(Ce)-Pr-Nd, (Pm)-Sm-Eu-Gd, Gd-TbDy-Ho or Er-Tm-Yb-Lu], except Ce, exhibits four curves, the features of which we attributed to the REE tetrad effect (Akagi et al., 1993). Lanthanite shows a steep descending slope toward heavier REE (Fig. 3). Again a similar aberration at Gd can be seen in the pattern of lanthanite. The most remarkable feature common to all of the three minerals is a strong Ce anomaly. As far as we know, REE patterns having a Ce anomaly of this magnitude have not been reported.

As can be seen in Fig. 4, the REE patterns of unleached and leached basalt- $\mathrm{A}$, and $\mathrm{HCl}$ leacheate from the basalt-A (calculated as the difference

Table 1. REE abundances ${ }^{a)}$ (ppm) of kimuraites, lanthanite and basalts

\begin{tabular}{|c|c|c|c|c|c|c|c|}
\hline Sample & $\mathrm{La}$ & $\mathrm{Ce}$ & Pr & $\mathrm{Nd}$ & Sm & $\mathrm{Eu}$ & Gd \\
\hline Kimuraite $^{\text {b) }}$ & & & & . & & & \\
\hline middle & 4940 & 10 & - & 31600 & 16900 & 8650 & 51700 \\
\hline middle* & 4780 & 7 & 3490 & 31600 & 17800 & 8950 & 52200 \\
\hline inner & 5970 & 13.6 & - & 19600 & 7860 & 3880 & 27000 \\
\hline inner* & 5770 & 9 & 2690 & 19600 & 7970 & 3900 & 26900 \\
\hline $\begin{array}{l}\text { lanthanite } \\
\text { basalt- } A^{c)}\end{array}$ & 151000 & 101 & - & 163000 & 30500 & 8890 & 28500 \\
\hline original & 57.1 & 53.6 & - & 87.1 & 19.3 & 6.64 & 24.0 \\
\hline leached & 26.4 & 48.2 & - & 34.9 & 9.16 & 3.15 & 12.0 \\
\hline leacheate ${ }^{d)}$ & 30.7 & 5.46 & - & 52.2 & 10.1 & 3.49 & 12.0 \\
\hline basalt- $\mathrm{B}^{\mathrm{e})}$ & 33.3 & 63.2 & - & 34.4 & 7.90 & 2.72 & 8.90 \\
\hline
\end{tabular}

\begin{tabular}{|c|c|c|c|c|c|c|c|}
\hline Sample & $\mathrm{Tb}$ & Dy & Ho & $\mathrm{Er}$ & $\operatorname{Tm}$ & $\mathrm{Yb}$ & $\mathrm{Lu}$ \\
\hline \multicolumn{8}{|l|}{ Kimuraite $^{\text {b) }}$} \\
\hline middle & - & 40700 & - & 15700 & - & 3970 & 489 \\
\hline middle* & 7480 & 40800 & 7630 & 15200 & 1080 & 3850 & 481 \\
\hline inner & - & 25900 & - & 15100 & - & 4880 & 614 \\
\hline inner* & 4210 & 27000 & 6220 & 15900 & 1440 & 5070 & 632 \\
\hline $\begin{array}{l}\text { lanthanite } \\
\text { basalt- }^{\text {c) }}\end{array}$ & - & 5940 & - & 734 & - & 91.9 & 8.75 \\
\hline original & - & 19.0 & - & 10.3 & - & 11.3 & 1.90 \\
\hline leached & - & 12.8 & - & 7.93 & - & 9.76 & 1.59 \\
\hline leacheate $^{\mathrm{d})}$ & - & 6.22 & - & 2.33 & - & 1.55 & 0.313 \\
\hline basalt- $\mathrm{B}^{\mathrm{e})}$ & - & 8.91 & - & 5.60 & - & 4.99 & 0.786 \\
\hline
\end{tabular}

a) Measured by TIMS-ID. The two asterisked samples are measured by ICP-MS.

${ }^{b)}$ Cited from Akagi et al. (1993).

c) Kimuraite-bearing basalt.

${ }^{d)}$ Calculated as the difference between REE abundances in the original and leached basalt.

e) This sample is taken from the kimuraite-bearing basalt, but importantly does not contain fissure minerals. 


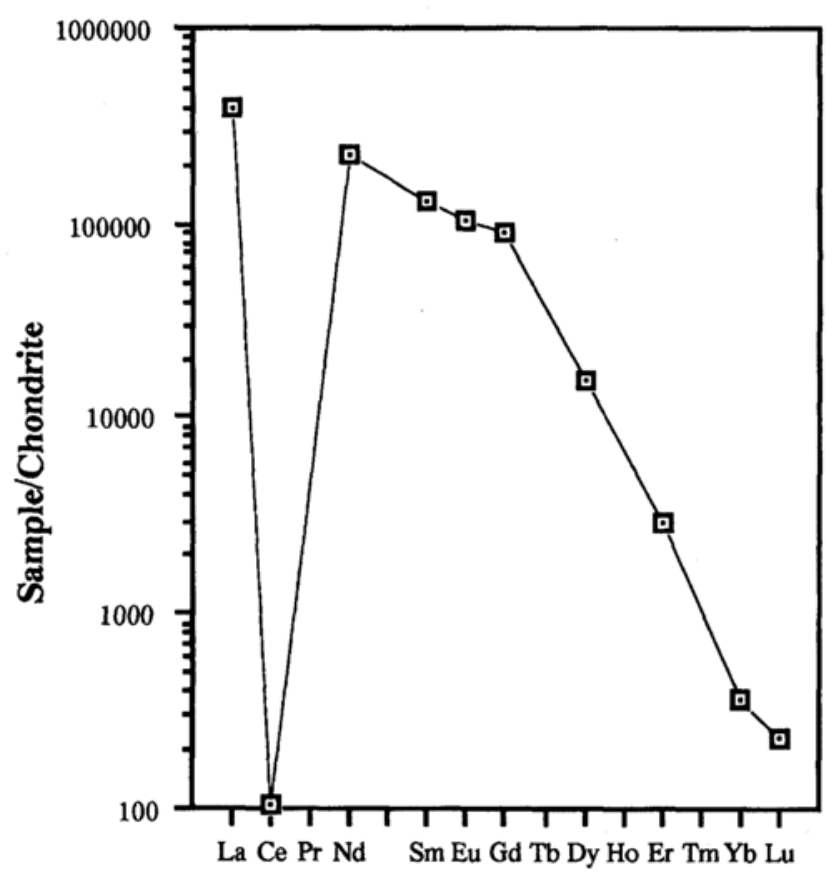

Fig. 3. REE pattern of lanthanite covering kimuraite (middle layer). Normalizing values are from Masuda et al. (1973) and Masuda (1975).

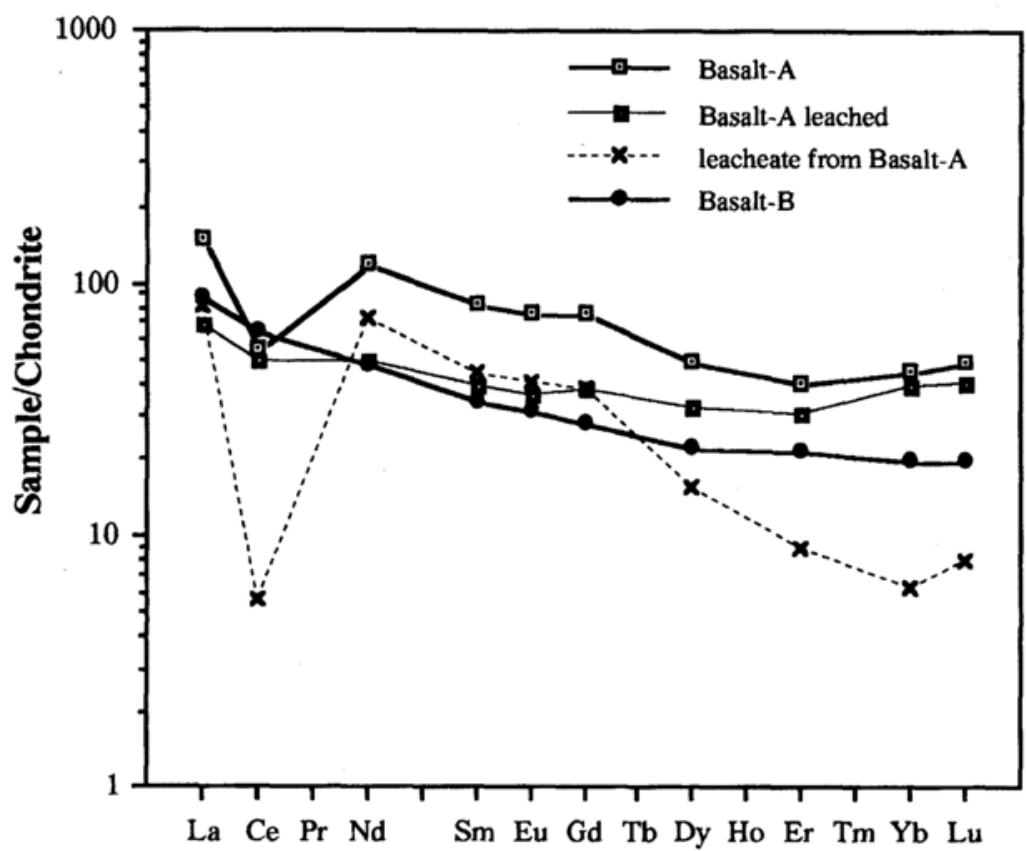

Fig. 4. REE patterns of basalt-A (kimuraite-bearing basalt), basalt- $\mathrm{A}$ leached by $\mathrm{HCl}, \mathrm{HCl}$ leacheate from basalt- $A$ and basalt-B (basalt having no fissure, sampled from the rock body of basalt- $A$ ). The pattern of $\mathrm{HCl}$ leacheate is calculated as the difference between basalt-A and leached basalt-A. Normalizing values are from Masuda et al. (1973) and Masuda (1975). 
Table 2. Nd isotope ratios of kimuraite and basalt

\begin{tabular}{lccc}
\hline \multicolumn{1}{c}{ Sample } & ${ }^{143} \mathrm{Nd}^{144} \mathrm{Nd}^{\mathrm{a})}$ & $\mathrm{Sm} / \mathrm{Nd}$ & $\varepsilon_{\mathrm{Nd}}{ }^{\mathrm{b})}$ \\
\hline Kimuraite middle & $0.512580 \pm 4$ & 0.535 & -1.13 \\
basalt-A $^{\mathrm{c})}$ & $0.512681 \pm 8$ & 0.262 & +0.84 \\
\hline
\end{tabular}

a) Normalized to ${ }^{146} \mathrm{Nd} /{ }^{144} \mathrm{Nd}=0.7219$. Errors are $2 \sigma$.

b) Present value.

c) Basalt leached with $\mathrm{HCl}$ solution.

between leached and unleached basalt-A) have some of the same features as kimuraite; i.e. a negative $\mathrm{Ce}$ anomaly and a cusp at $\mathrm{Gd}$, although both the features are more subdued than in kimuraite. The features become less conspicious in order of leachate, basalt-A and leached basaltA. The shapes of these patterns are noticeably different from those of common basalts. The REE pattern of basalt-B, which contains no REE fissure minerals, has a pattern similar to ordinary basalts (see Fig. 4). The pattern of basalt-B is more similar to that of leached basalt-A than to that of unleached basalt-A. The REE abundances in basalt-A are also much higher than those in basaltB.

\section{Isotopic abundance of neodymium in kimuraite and basalt}

Table 2 gives the ${ }^{143} \mathrm{Nd} /{ }^{144} \mathrm{Nd}$ ratios in kimuraite (middle layer) and in the leached basaltA. The measurement of kimuraite and the leached basalt was done 4 times and twice, respectively, and the results in Table 2 show the average and external deviation. The Nd isotope ratio of basalt was significantly higher than that of kimuraite by about $0.0001(2 \sigma=0.000009), 2$ in $\varepsilon_{\mathrm{Nd}}$ value.

\section{Discussion}

\section{Association of water}

The following three facts strongly support that the REE in kimuraite has been once resolved in an aqueous solution. Firstly, as can be seen in Fig. 1, the REE patterns of kimuraite exhibit remarkable negative anomalies of $\mathrm{Ce}$, which amount to more than three order of magnitude. Such a strong anomaly indicates not only that $\mathrm{Ce}$ has an abnormal valency of $4+$, but also that the REE has once been in solution for the following reason. The segregation of Ce can most reasonably be explained by selective precipitation of $\mathrm{Ce}^{4+}$, which is perpetually supplied from $\mathrm{Ce}^{3+}$ to satisfy the redox equilibrium of the solution. The precipitation is also effected by high concentration of REE in the solution, where the concentrations of $\mathrm{Ce}^{4+}$ species exceed their solubility. The Ce anomaly of kimuraite suggests an aqueous ore solution enriched in REE as the source of REE in this mineral. Secondly, kimuraite and its related minerals are water-bearing minerals, and water is necessary for the formation of the minerals. Their occurrence directly suggests an aqueous liquid as a source of the REE of the minerals. Finally, as indicated earlier, the tetrad effect appears in distribution ratios between solid and aqueous phases, and the W-type tetrad effect corresponds to the aqueous and solid ratio of REE. The appearance of the tetrad effect in kimuraite implies the REE in kimuraite has once been in an aqueous phase as the result of water-rock interaction.

\section{Relationship among kimuraite and its related minerals}

As shown in Fig. 2, kimuraite and lanthanite in the specimen studied occur in a spherical habit with lanthanite covering kimuraite (middle layer). The layering of lanthanite and kimuraite suggests that these minerals have crystallized originally from a liquid, the composition of which changes during the course of the crystallization.

In Fig. 5 the abundance ratios of REE among the minerals are plotted on a logarithmic scale. The abundance ratios of kimuraite (middle layer) to kimuraite (inner layer), and of lanthanite (outer layer) to kimuraite (middle layer) form much simpler and smoother patterns than their chondritenormalized REE patterns (Figs. 1 and 3). The abundance ratio of kimuraite (middle layer) to kimuraite (inner layer) shows a convex-upward curve with a maximum between $\mathrm{Sm}$ and $\mathrm{Eu}$. The ratio of lanthanite to kimuraite (middle layer) gives a steep curve descending as the atomic number 

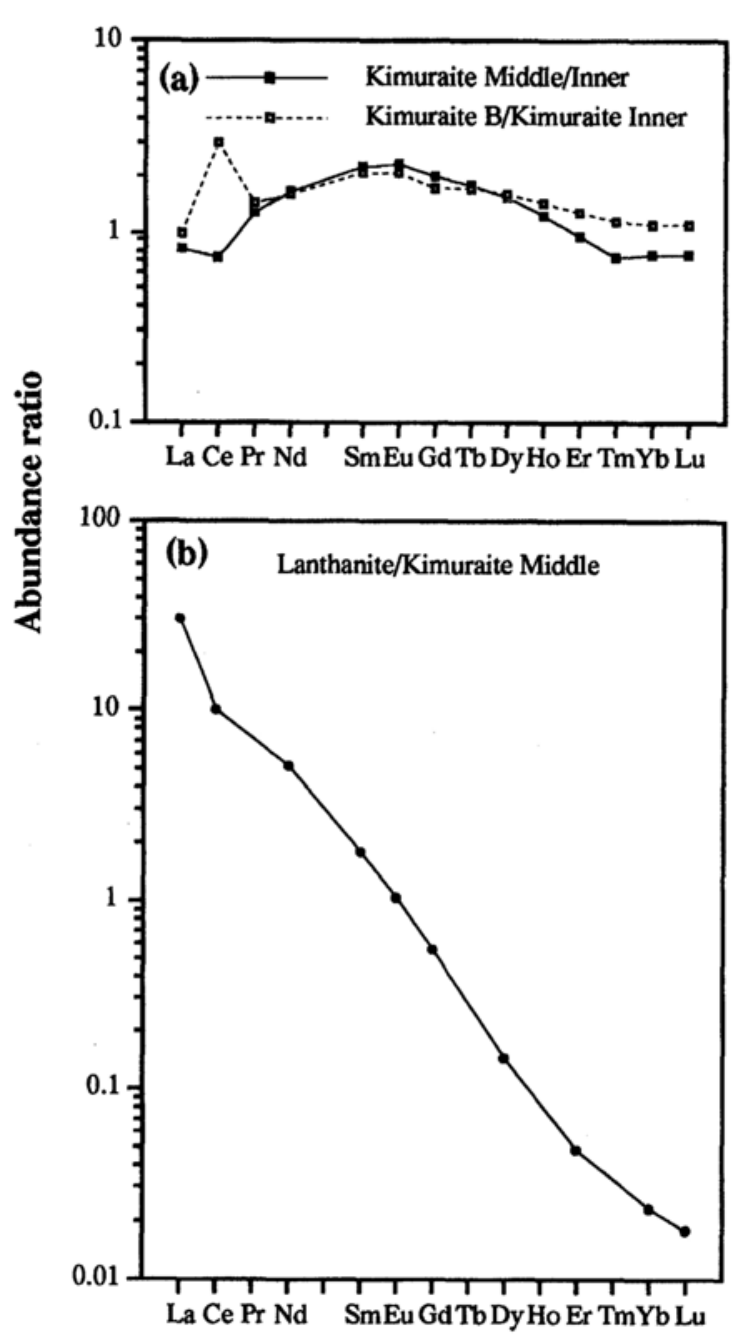

Fig. 5. (a) REE abundance ratios of kimuraite (middle layer) to kimuraite (inner layer) and of kimuraite- $B$ to kimuraite (middle layer). The data of kimuraite- $B$ is from Akagi et al. (1993). (b) REE abundance ratio of lanthanite to kimuraite (middle layer).

increases. The abundance ratios have neither an $\mathrm{Eu}$ anomaly nor a pronounced Gd aberration (Fig. 5). The smooth patterns, together with the feature of their occurrence, suggest that the two kimuraites and lanthanite developed from a single source.

Nagashima et al. (1986) suggested that kimuraite and lanthanite formed during the hydration of lokkaite through the stoichiometric reaction:

$$
\text { lokkaite }+5 \mathrm{H}_{2} \mathrm{O}=\text { lanthanite }+ \text { kimuraite. }
$$

They, however, failed to show the mass balance among the three minerals, indicating that kimuraite and lanthanite could form rather directly from a single ore solution.

It is an interesting question to consider whether all of these related minerals show the tetrad effect. Nagashima et al. (1986) reported the REE composition of these paragenetic minerals. To analyze them, however, they used ICP-AES which is vulnerable to severe inter-REE spectral interference. (In fact, one of the present authors, T. A., measured the samples for them. Accordingly, we are able to re-evaluate their data.) Toyoda and Haraguchi (1987) reported an example of interREE spectral interference factors, with the same ICP-AES machine as Nagashima et al. (1986) used, but which varied depending on the operating condition of the machine. We have found that their data of $\mathrm{Ce}, \mathrm{Pr}, \mathrm{Tb}, \mathrm{Ho}$ and $\mathrm{Tm}$ are too large due to spectral interferences from $\mathrm{Pr}, \mathrm{Nd}, \mathrm{Gd}$ and Dy. (1000 ppm of $\mathrm{Nd}$ gives a baseline enhancement equivalent to $70 \mathrm{ppm}$ of $\mathrm{Pr}$, and so on.) Thus, it is not adequate to discern the tetrad effect from the data of Nagashima et al. (1986). We think it is rational to judge the presence of this effect from our data on kimuraite and lanthanite. The fading of the tetrad effect in Figs. 5(a) and (b) obviously shows that lanthanite and kimuraite have the same degree of W-type tetrad effect, implying that lokkaite, the precursor mineral of the both, should also exhibit the W-type tetrad effect, if the process proposed by Nagashima et al. (1986) is correct. The ore solution for kimuraite and the related minerals are very likely to show the tetrad effect.

Both of the abundance ratio curves (solid lines in Figs. 5(a) and (b)) show a negative Ce anomaly of about the same magnitude. This implies that only Ce had an abnormal valency of 4+ during the crystallization, whereas other REE were trivalent. Thus in the course of the crystallization, only $\mathrm{Ce}$ has distributed in the crystals under a partition equilibrium different to those of other REE. 


\section{Octad effect}

The pattern of kimuraite (middle layer)/ kimuraite (inner layer) (Fig. 5(a)) shows a slight aberration at Gd, but it is not clear at present whether this aberration is due to the tetrad effect or something else such as the "octad effect" (an effect producing a double-arc distribution pattern, each arc consisting of eight elements; La-Ce-PrNd-Pm-Sm-Eu-Gd, Gd-Tb-Dy-Ho-Er-Tm-Yb-Lu, on the analogy of the tetrad effect). A similar octad effect has already been pointed out by Masuda $e t$ al. (1987) in the distribution ratio of REE between two leucogranites from China. This aberration of Gd is unlikely to be due to an analytical error. Any systematic analytical error on the Gd concentration data would have been already negated by dividing one datum by another. Furthermore, dividing the data of kimuraite from another fissure (kimuraite-B, cited from Akagi et al., 1993) by those of kimuraite (inner layer) also demonstrate a similar aberration at $\mathrm{Gd}$, as shown by the dashed line in Fig. 5.

\section{Origin of REE based on Nd isotope composition}

The Nd isotopic composition of kimuraite is lower than that of the host basalt by nearly $2 \varepsilon$ units. It should be noted that the abundance ratio of $\mathrm{Sm} / \mathrm{Nd}$ in kimuraite is higher than that of basalt (see Table 2) and the age of the basalt is later than Pleistocene period (Nagashima et al., 1986; Kagami et al., 1987). It is simply impossible to explain the lower ${ }^{143} \mathrm{Nd} /{ }^{144} \mathrm{Nd}$ ratio of kimuraite by the idea that the REE in kimuraite originated from the host basalt. Even if the basalt formed $10^{7}$ years ago, the initial $\mathrm{Nd}$ isotope ratio of the basalt is still higher than the present ratio of kimuraite, which definitely rules out a genetic relationship between kimuraite and the host basalt. We cannot deny the possibility of the contamination of REE from basalt during the ascent of the ore solution. If it is the case, we have to consider much lower ${ }^{143} \mathrm{Nd} /{ }^{144} \mathrm{Nd}$ ratio for the ore solution, which eventually convinces the absence of genetic relationship between the ore solution and basalt.

The REE in kimuraite should have spent a significant period (at least $10^{8}$ year, much longer than the age of the host basalt) in an environment having a lower $\mathrm{Sm} / \mathrm{Nd}$ ratio than the host basalt or in other words, in an LREE-enriched environment. It is interesting to note that the $\mathrm{Nd}$ isotope ratio of kimuraite is identical to that of Pacific Ocean water (and that Pacific Ocean water also exhibits a W-type tetrad effect). A standard rock JB-1, alkali basalt from Myokanji Toge, Nagasaki, near the locality of kimuraite occurrence, has a ${ }^{143} \mathrm{Nd} /{ }^{144} \mathrm{Nd}$ ratio of 0.512786 (Kagami et al., 1987). The isotope ratio of the leached basalt- $A$ is close to that of JB-1, although it is still lower than that of JB-1. (Perhaps, some amount of kimuraite-derived neodymium remained in the basalt sample after the $\mathrm{HCl}$ leaching, lowering the isotope ratio of the leached basalt-A.) The kimuraite-bearing basalt is very common basalt; the source of REE in kimuraite should be sought in some LREE-enriched environment like crust, which is understood to be the main source for $\mathrm{Nd}$ in ocean water.

\section{Relationship between kimuraite and the host basalt}

The REE pattern of the $\mathrm{HCl}$ leacheate from basalt (Fig. 4) appears to indicate a tetrad effect, although it is not so clear as that of kimuraite. The abundance ratio of kimuraite (middle layer) to the $\mathrm{HCl}$ leacheate from basalt forms a smooth curve (Ce has been omitted because of its abnormal valency) with a maximum between Dy and Er (Fig. 6). This simple and smooth curve suggests that the REE in kimuraite and in the leacheate of basalt are cogenetic, and that the leacheate shows a tetrad effect of similar magnitude to that of kimuraite. Taking the discrepancy of the $\mathrm{Nd}$ isotope ratio between kimuraite and basalt into consideration, it is most likely that the fluids responsible for the crystallization of kimuraite in fissures also infiltrated or altered the host basalt as well. The substance which permeated into basalt is probably a hydrothermal aqueous solution similar in composition to the original ore solution for kimuraite and the related minerals.

It is worthwhile to note that the curve in Fig. 6 appears to consist of two straight lines crossing between Dy and Ho, which are symmetrical about 


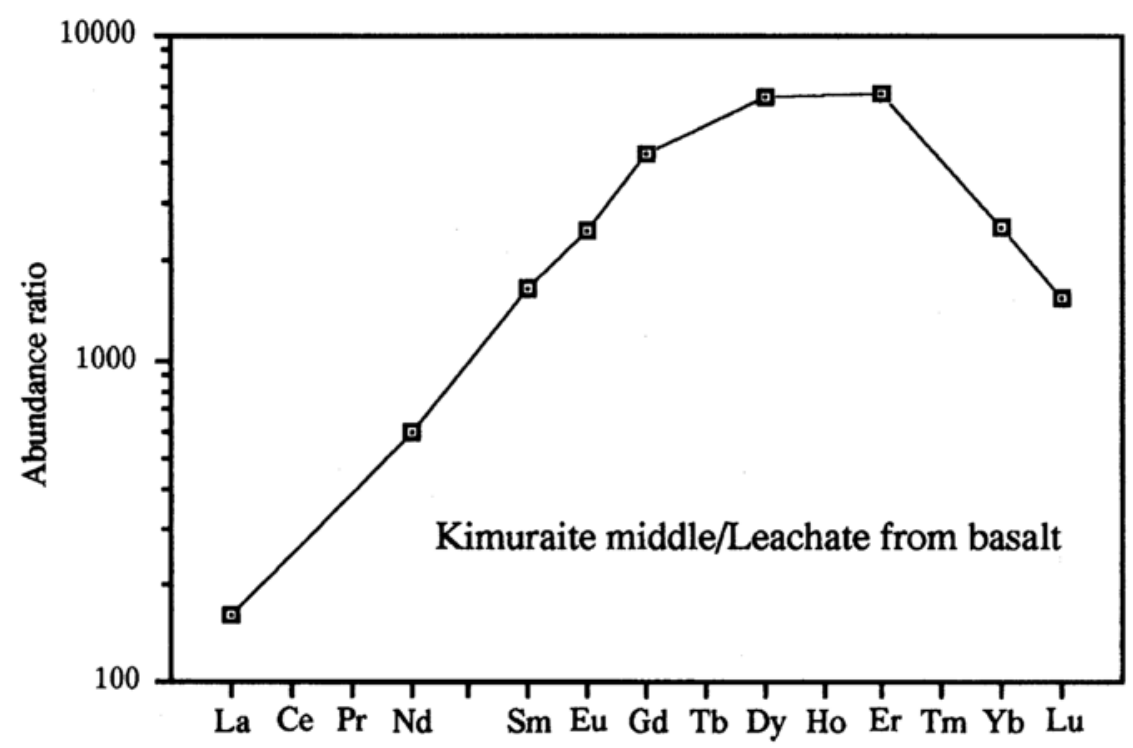

Fig. 6. REE abundance ratio of kimuraite (middle layer) to $\mathrm{HCl}$ leacheate from basalt-A.

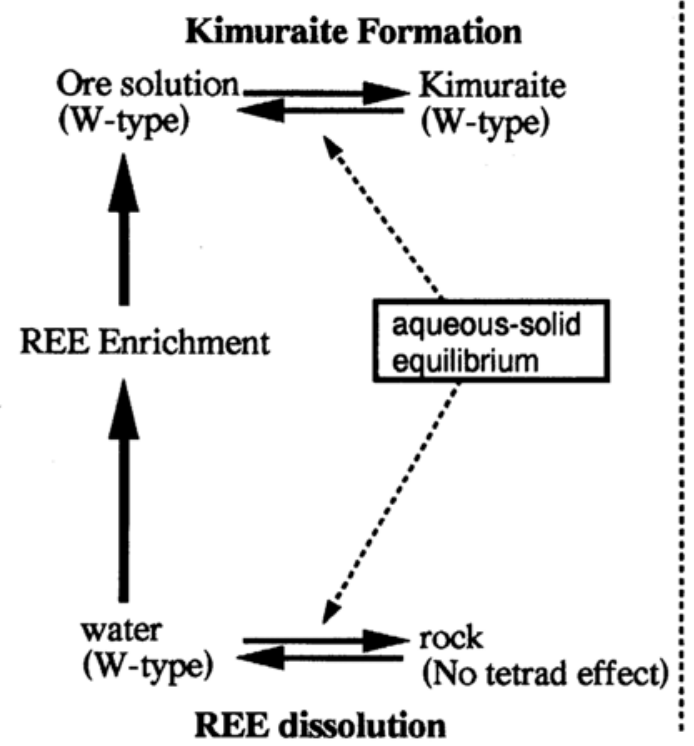

\section{Appearance of tetrad effect}

$\frac{\text { Kimuraite }}{\text { Ore solution }}$ weak M-type?

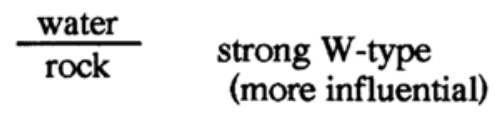

Fig. 7. The inferred history of kimuraite formation and the possible stages causing the tetrad effect.

a vertical axis through this break point. The ionic radius of $\mathrm{Y}$ is between those of Dy and Ho. If we accept that this curve mainly reflects the effect of $\mathrm{Y}$ on the distributions of REE between kimuraite and the ore solution permeating into basalt, one of the interpretations of this curve is that $\mathrm{Y}$ is structually or crystallo-chemically necessary in the process of the kimuraite crystallization. 
Genesis of kimuraite and appearance of tetrad effect

The comparison of $\mathrm{Nd}$ isotopes and REE patterns between kimuraite and its host rock suggest that their origins are different, therefore the origin of the tetrad effect has no connection with the host basalt. The distribution of REE in the related minerals and the appearance of the tetrad effect would suggest that kimuraite and the related minerals formed from an aqueous solution, and this solution is considered to have already undergone a process producing the tetrad effect. If the partition of REE between aqueous and solid phases is accepted as the cause of the tetrad effect, at least two stages are conceivable for the appearance of the effect. In Fig. 7 the stages are shown schematically along with the shape of REE pattern of rocks or aqueous solutions. The first one is the elution of REE from the rocks into water, the second one is the crystallization of kimuraite and the related minerals from aqueous ore solution. In both the stages, the relative REE abundance of the solid phase to the aqueous phase is considered to show the M-type tetrad effect from the empirical rule. It is concluded from our observation of the W-type tetrad effect in kimuraite that the first stage is the most influential for the appearance of the tetrad effect.

Acknowledgments - We are grateful to Mr. Shoichiro Iwano for sampling basalts. Thanks are also extended to Dr. Izumi Nakai, University of Tsukuba, for his appropriate and very useful advice in this study. The present research has been partially supported by a Grant-in-Aid for Scientific Research from the Ministry of Education, Science and Culture, Japan.

\section{REFERENCES}

Akagi, T., Shabani, M. B. and Masuda, A. (1993) Lanthanide tetrad effect in kimuraite $\left[\mathrm{CaY}_{2}\left(\mathrm{CO}_{3}\right)_{4} \cdot 6 \mathrm{H}_{2} \mathrm{O}\right]$ : implication of a new geochemical index. Geochim. Cosmochim. Acta 57, 2899-2905.

Jørgensen, C. K. (1979) Theoretical chemistry of rare earths. Handbook on the Physics and Chemistry of Rare Earth. Vol. 3, 111-169, North-Holland, Amsterdam.
Kagami, H., Iwata, M., Sano, S. and Hinma, H. (1987) $\mathrm{Sr}$ and $\mathrm{Nd}$ isotopic compositions and $\mathrm{Rb}, \mathrm{Sr}, \mathrm{Sm}$ and $\mathrm{Nd}$ concentrations of standard samples. Technical Report of Institute for Study of the Earth Interior, Okayama University, Series B. No. 4, 1-16.

Kagi, H., Dohmoto, Y., Takano, S. and Masuda, A. (1993) Tetrad effect in lanthanide partitioning between calcium sulfate crystal and its saturated solution. Chem. Geol. 107, 71-82.

Kawabe, I. (1992) Lanthanide tetrad effect in the $\mathrm{Ln}^{3+}$ ionic radii and refined spin-pairing energy theory. Geochem. J. 26, 309-335.

Liu, C.-Q., Masuda, A., Okada, A., Yabuki, S., Zhang, J. and Fan, Z.-L. (1993) A geochemical study of loess and desert sand in northern China: implications for continental crust weathering and composition. Chem. Geol. 106, 359-374.

Masuda, A. (1975) Abundances of monoisotopic REE, consistent with the Leedey chondrite values. Geochim. J. 9, 183-184.

Masuda, A. and Akagi, T. (1989) Lanthanide tetrad effect observed in leucogranites from China. Geochem. J. 23, 245-253.

Masuda, A. and Ikeuchi, Y. (1979) Lanthanide tetrad effect observed in marine environment. Geochem. J. 13, 19-22.

Masuda, A., Kawakami, O., Dohmoto, Y. and Takenaka, T. (1987) Lanthanide tetrad effects in nature: two mutually opposite types, $\mathrm{W}$ and $\mathrm{M}$. Geochem. J. 21, 119-124.

Masuda, A., Nakamura, N. and Tanaka, T. (1973) Fine structures of mutually normalized rare earth patterns of chondrites. Geochim. Cosmochim. Acta 37, 239248.

McLennan, S. M. (1994) Rare earth element geochemistry and the "tetrad" effect. Geochim. Cosmochim. Acta 58, 2025-2033.

Nagashima, K., Miyawaki, R., Takase, J., Nakai, I., Sakurai, K., Matsubara, S., Kato, A. and Iwano, S. (1986) Kimuraite, $\mathrm{CaY}_{2}\left(\mathrm{CO}_{3}\right)_{4} \cdot 6 \mathrm{H}_{2} \mathrm{O}$, a new mineral from fissures in an alkali olivine basalt from Saga Prefecture, Japan, a new data on lokkaite. Amer. Mineral. 71, 1028-1033.

Peppard, D. F., Mason, G. W. and Lewey, S. (1969) A tetrad effect in the liquid-liquid extraction ordering of lanthanides (III). J. Inorg. Nuclear Chem. 31, 2271-2272.

Toyoda, Y. and Haraguchi, H. (1987) Geochemical characterization of geological standard rock samples from rare earth element distribution patterns measured by inductively coupled plasma atomic emission spectrometry. Bull. Chem. Soc. Jpn. 60, 933-939. 